\title{
A CYBERNETIC APPROACH TO ORGANIZATIONAL RESILIENCE
}

\author{
Author(s) / Auteur(s) : \\ Victoria A. ZGOUVA \\ Auditor in the Hellenic Court of Audit; CSAP Post graduate student \\ University of Piraeus, Department of Informatics \\ Court of Audit of the Hellenic Republic; Ministry of Justice, Transparency and Human Rights; \\ zgouva.vicky@gmail.com
}

Dimitrios S.VARSOS

Management system consultant; CSAP Lecturer

University of Piraeus, Department of Informatics; Hellenic Society for Systemic Studies (HSSS);

MSI Hellas Consulting Group

dvarsos@msi.gr

Nikitas A. ASSIMAKOPOULOS

Emeritus Professor

University of Piraeus, Department of Informatics; Hellenic Society for Systemic Studies (HSSS)

assinik@unipi.gr

\begin{abstract}
Résumé :
The modern organization operates in a dynamic environment where ambiguity and uncertainty abound. As an open social system that functions in a continuously evolving business context, the modern organization must determine the external and internal issues that are relevant to its purpose and its strategic direction, and continually align its governance and management models, in a manner that reflects the diversity of this context. Embracing an organizational resilience paradigm, augments traditional risk management efforts and promotes the optimization of key and enabling processes, across all functions and levels of the organization. On a practical level, organizational resilience can be instrumental in improving management performance and an impetus to anticipating future threats and opportunities. Moreover, it can reinforce the organization's capacity to monitor developing trends, as well as its ability to respond proactively to a variety of events, while learning from past successes and failures. Finally, implementing an effective internal control framework, combined with sufficient internal audit processes, will ensure that operational and tactical actions are aligned with strategic priorities that are consistent with the culture of the business, and in line with the organization's overall risk tolerance. In this work we make use of the cybernetic structure of the Viable System Model (VSM) to both identify and diagnose the pathologies commonly found in traditional organizations, and explore its practical potential, in developing and implementing redesign initiatives, which reinforce the organization's resilience and agility.
\end{abstract}

\section{Keywords / Mots-clés :}

Resilience theory, organizational resilience, Viable System Model (VSM), organizational design, systems approach, strategic adaptability.

\section{INTRODUCTION}

Resilience theory has become a prevalent issue in recent years. Nonetheless, there is divergent opinion relative to what exactly the term "resilience" denotes, and how organizations can embody resilience in their structures and functions. Organizational resilience refers to an entity's ability to anticipate, prepare for, respond, and adapt to incremental change and sudden disruptions, in order to achieve the intended results that are associated with its purpose. On a practical level, this definition implies the 
capacity to "bounce-back" from failure, and to take advantage of lessons learned in a manner that turns potential threats into leveraged opportunities. Given the complexity that is embedded in the modern organization's environment, as well as the ever-present risk that is the effect of the uncertainty that emerges from this complexity, decision-makers must cultivate structural arrangements, which balance the necessary controls that preserve consistency of purpose, with the necessary adaptability and resilience that allows their organization to respond effectively to conditions in a state of constant unrest. In this context, resilience theory addresses uncertainty from a holistic perspective, through a structured process that supports decision-makers in identifying, managing, and monitoring the organization's critical risks, while ensuring that the process itself is continually improved as the business environment changes. In short, embedding resilience in the organization's structures and processes can be an effective management tool for assessing both the threats and the opportunities that arise from risk, contributing to the improvement of the organization's overall performance.

In this work, we explore the manner in which an organization can achieve resilience, and the practical means with which to integrate resilience into its structures and functions, thus maximizing its strategic capabilities. The cybernetic framework of the Viable Systems Model (VSM), is used to evaluate the traditional hierarchical edifice of organization. The model is a powerful tool that can be instrumental in identifying the functional incongruities and communication disconnects, which hinder synergies and the organization's overall resilience. A prerequisite to organizational transformation, is the cultivation of an adaptable culture that is propagated through flexible structures, which are built on open communication channels and people-centered tenets and values. In this regard, the organization is treated as a living system, which just like any other organism that is addressed by Darwinian theory of evolution: "it's not the strongest species that survive, nor the most intelligent, but the most responsive to change."

\subsection{Paper Structure}

This introduction is followed by a brief overview of common terms and concepts that are relevant to systems science, which we use throughout the article. We continue by describing the structural deficiencies of the traditional "top-down" type of organization. Then follows a brief description of the key components of resilience, and the four cornerstones on which organizational resilience is built. We then compare and contrast the basic tenets of traditional risk management and organizational resilience and highlight the significance of internal control and internal audit in enhancing organizational resilience. A brief description of the VSM and the principles on which the model is based is provided. The VSM, together with internal control processes are then employed to transform a traditional, into a resilient organization, describing the necessary interventions that should be carried out in its structure. The article concludes with a brief discussion of the advantages of an organization that is organized along the recursive structure of the VSM and remarks for future research.

\section{A SYSTEMS APPROACH TO ORGANIZATIONAL RESILIENCE: A BRIEF OVERVIEW}

\subsection{The Organization Viewed as an Open System}

An organization may be viewed as a purposefully organized open system, which is composed of a bounded set of interconnected and interdependent elements that work together in order to achieve one or more desired outcomes (e.g., Flood \& Carson, 1988; Ackoff, 1999). As an integral part of a unified whole, each element affects and is affected by every other element in the set, and through its actions and interactions contributes to the function of the whole, relative to its desired outcomes (von Bertalanffy, 1950; Ackoff, 1999). Function refers to the production of the outcomes that define the organization's purpose (Ackoff, 1971). The network of interactions among the elements composes the 
system's structure. Structure, therefore, refers to the connections that exist among the system's elements, which impose certain constraints on the system's function (Varsos and Assimakopoulos, 2018). Subsets of closely coupled elements and the relations that hold them together form subsystems, which perform specific functions as parts of the system's overall structure. The internal processes that exist among the system's elements, which determine the dynamics of the interactions that constitute the system as a coherent functional whole, are referred to as the system's organization (Maturana \& Varela, 1980). A system is said to be effective when its structure has the capacity to realize through its function the system's overall desired outcomes. In turn, a system's efficiency is expressed as the ratio between the system's useful output to total input.

As an open social system, the organization interacts with its external environment, which is itself a higher order system of increased complexity that is composed of its own elements that can be arranged into subsystems (von Bertalanffy, 1950). An open system secures input from its environment in the form of material, information, and energy, and through its function transforms this input into output (products and/or services), which it then releases back to the environment. Figure 1 illustrates the organization as an open system with its boundaries and its relationship with the external environment.

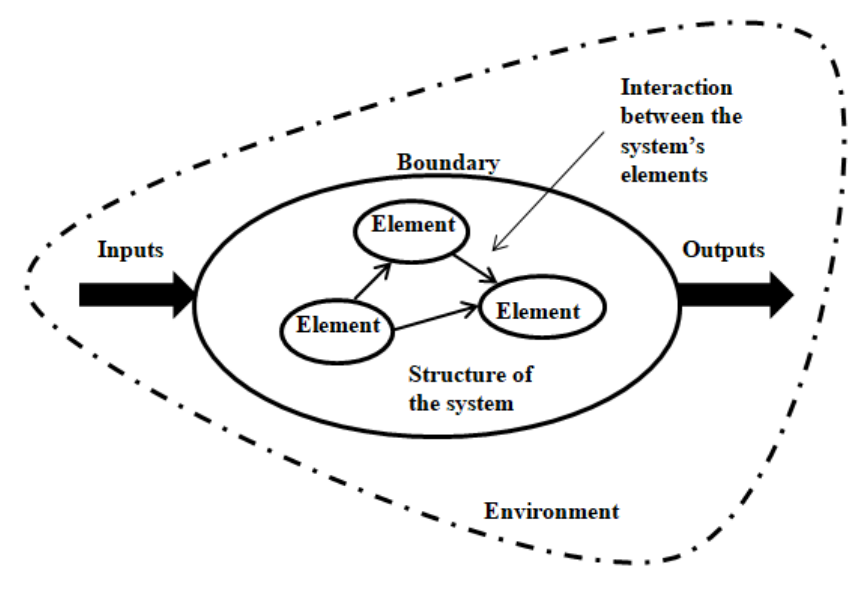

Figure 1.Organization as a simple open system.

\subsection{The Traditional Approach to Organization and Management}

Understanding the organization's structure is essential to the evaluation of its viability and in diagnosing the potential issues that hinder synergy, cohesion, and resilience. In a traditional top-down organization, work activities are grouped together along common areas of responsibility and executed with minimum attention given to functional integration, promoting a high degree of horizontal specialization (Scott \& Davis, 2007). The activities carried out by the various operational units (e.g., divisions, departments, offices) are directed and controlled through a formal hierarchy of command and control, resulting in vertical differentiation. Official communication networks facilitate information transfer between the operational units consistent with the requirements of mandated policies and standardized procedures. The higher organization levels (or decision-making function) inform the operational units through formal instructions and/or commands that direct all product and/or service realization activities. Communication ascending from the operational units at the request of the decision-making function takes place in the form of formal reports, which are commonly associated with productivity results. Treatment of conditions that require attention is derived through the use of analytical methods that rely on cause and effect relationships. Interventions focus on increasing the efficiency of isolated work activities, functions, and/or structures, often at the cost of overall effectiveness. Barlas (2007) argues that any kind of a system (e.g., financial, social, 
political, educational, biological or production), consists of many interrelated elements interacting in a meaningful way, so that it can presumably serve its purpose". He further argues, that "the structure creates the behavior" of the system (Barlas, 2007).

Change in the traditional top-down organization unfolds within the boundaries of existing rules and norms that govern structural and/or behavioral relationships, in an attempt to shift from one stable state to the next, through planned actions that progress in linear, incremental stages (Morgan, 1986). The decision-making function formulates change initiatives and passes them on to the operational levels for implementation. The initiatives target the "parts" of the organization that require action, with little attention given to long-term systemic results. Individuals with formal managerial and/or administrative authority control the deployment of change initiatives within the policy boundaries of the specific operational units (Varsos \& Assimakopoulos, 2016). Employee engagement is pursued as an extension of organizational objectives and goals. In this context, little attention is paid to the "human" aspect of the organization, including individual needs and wants (Morgan, 1986). Thus, the focus centers on the technical character of the work activities performed, promoting optimal efficiency and increased productivity through the automation of manual labor, rigid hierarchical authority structures, and the elimination of redundancy (Varsos \& Assimakopoulos, 2018).

It is not uncommon, however, for the various operational units that compose an organization, to have multiple purposes and pursue diverse goals. Moreover, the operational units function under varied conditions and are often subject to different environmental influences and risks. Managing these influences and risks is complicated further by the fact that a change initiative at one operational level or function, is likely to have unforeseen consequences and risks at other levels and functions, and different short- and long-term results (Assimakopoulos \& Varsos, 2015). Consequently, excessive control often constricts the capacity of the operational units' ability to adapt to changing environmental conditions, and ultimately, the organization's overall agility and resilience to environmental perturbations (Varsos \& Assimakopoulos, 2016). Thus, implementing an effective riskbased change strategy in response to environmental perturbations, at any level of the organization, requires an understanding of the systemic relationships that exist among the various system elements, both within the organization and between the organization and its environment (Assimakopoulos \& Varsos, 2015).

\subsection{Organizational Resilience: Overview of Terms and Concepts}

The original notion of the term "resilience" stems from the Latin word resilire or resilio and means "jump back" or "bounce back" (Manyena, et.al., 2011; Alexander, 2013). Resilience is a ubiquitous concept, which has become increasingly popular in research across many disciplines (Sharifi \& Yamagata, 2016), including economics (Arthur, et.al., 1999), sociology (Adger, 2000), healthcare and psychology, network and information security (Smith, et al., 2011), and urban and community planning. A resilience approach is also discussed for its vital role in guiding sustainable development policies and disaster risk management activities. Numerous approaches can be found in literature for resilience theory, which are not always consistent with each other, giving the term a polysemic character (Sharifi \& Yamagata, 2016). Holling (1973) argues that resilience theory has its roots in the science of ecology, where it "determines the persistence of relationships within a system and is a measure of the ability of these systems to absorb changes of state variables, driving variables, and parameters, and still persist".

The "bouncing-back" behavior of ecological systems is similar to the behavior of systems in engineering resilience. Specifically, resilience refers to "the resistance of a system to disturbance [perturbations] and the speed by which the system returns to equilibrium" (Mavhura \& Manyena, 2018). 
Over the years, resilience theory has become increasingly popular in the fields of risk mitigation and business continuity management. Burnard \& Bhamra (2011) define resilience as the ability of an element or a system to return to a stable condition after a disruption. Similarly, Denyer (2017) argues that a resilient organization is able to cope with the complexity, volatility, and uncertainty of its modern business context, by responding effectively to sudden disruptions, leveraging opportunities, as well as effectively adapting its function in a manner that improves its sustainable organizational performance.

\section{THE ORGANIZATIONAL RESILIENCE APPROACH}

\subsection{The New Paradigm of Resilient Organizations}

Given the ambiguity and uncertainty that is ever-present in the modern organization's business environment, the need to develop flexible and adaptive capabilities can be equated with survival. The structure of the traditional top-down organization often proves rigid and inflexible in addressing the increasing rate of change, as well as the complexity that is embedded in the organization's internal and external environment (Espejo \& Gill, 1997). To this extent, the development of the distinct but complementary capabilities of strategic agility and resilience capacity is critical to the organization's capacity to deal with a continuously evolving business environment (Lengnick-Hall \& Beck, 2009).

In systems terms, organizational resilience is not a condition that emerges from a static process. Instead, the process itself must change in response to the volatility of the external environment and as the capabilities of the organization transform over time. In this regard, the organization's ability to respond to unforeseen risks and develop its business continuity competences, is directly proportional to its increase of focus on resilient structures, and the investment made to support these structures (Gibson \& Tarrant, 2010). Given that a genetic "fit for purpose" organizational resilience model is not available, both public and private organizations (of any size or structure) can develop and implement a resilience approach by applying to their individual circumstances a specific framework of principles, attributes and activities that are prescribed in guidelines and standards ${ }^{1}$ published by prominent International Standards Organizations (NSW Government Treasury, 2018).

In short, building an agile organization that embodies organizational resilience, requires management intervention and reconfiguration of existing strategies, structures, processes, and technologies. An agile structure calls for building a dense network of empowered teams within a people-centered culture and implementing an interrelated network of coherent relations, which reflect and support the way in which the organization co-creates value for its stakeholders. It also requires adopting high standards of alignment, accountability, expertise, transparency, as well as maintaining coordination and collaboration within the organization. It is important to note that key to any restructuring initiative, is a focus on achieving the organization's goals and objectives effectively, while at the same time balancing stability and change in an uncertain and complex environment (Wouter, et.al., 2018).

\footnotetext{
1 These Standards include: BS 65000:2014 "Guidance on Organizational Resilience" published by the British Standard Institution (BSI); ISO22316:2017 "Security and Resilience - Guidelines for Organizational Resilience"; and ISO 22301: 2019 "Security and Resilience - Business Continuity Management Systems - Requirements" published by the International Organization for Standardization (ISO).
} 


\subsection{The Four Cornerstones of Organizational Resilience}

Long-term resilience requires a holistic approach in developing the organization's capabilities, which will enable it to thrive despite the complexity, the volatility, and the uncertainty of its business environment. Strategic adaptability, robust governance, and agile leadership are three key elements of a sound resilient structure. The interaction between these interdependent elements are paramount in managing the effects of a continually changing environment, taking measured risks with confidence, as well as responding effectively to opportunities and threats (Kerr, 2019). In this respect, organizational resilience would be more accurately defined as "a synonym for robustness" and "the graceful extensibility, when surprise challenges boundaries", rather than just as "a rebound from trauma and return to equilibrium" (Woods, 2015). It is essential to the organization's survival, therefore, to maintain broad dynamic capabilities that will enable it to adapt with success to unstable and complex environmental conditions (Burnard, Bhamra, \& Tsinopoulos, 2018).

In recent years, much attention has been paid to reducing the complexity of implementation of a resilient approach. Patriarca et.al. (2018) argue that organizational resilience emerges from a balanced combination of four non-linear and complementary cornerstones: (a) anticipating future threats and opportunities, (b) monitoring underway evolutions, (c) responding to any type of events and (d) learning from past failures and successes. Similarly, Denyer (2017) presented the 4Sight model, which treats organizational resilience as a coherent system that consists of a four-stage structure (Table 1). Denyer (2017) also supports that the 4Sight methodology can be combined with Deming's Plan-DoCheck-Act (PDCA) cycle, in order to achieve an even higher level of organizational resilience. This is supported by the argument that if flexibility (provided by the 4Sight methodology) is combined with consistency (provided by the PDCA cycle), organizations will be able to face large, complex issues, while simultaneously maintaining the continuous improvement of existing systems and processes.

Table 1: Comparing PDCA and 4Sight for Organizational Resilience. Source: Denyer (2017)

\begin{tabular}{|l|l|}
\hline PDCA Cycle & 4 Sight Approach \\
\hline Plan (Defining policy, objectives and targets) & Foresight (Anticipate, predict and prepare the future) \\
\hline $\begin{array}{l}\text { Do (Implement plans within a structured } \\
\text { management framework) }\end{array}$ & Insight (Interpret and respond to present conditions) \\
\hline $\begin{array}{l}\text { Check (Measure and monitor actual results } \\
\text { against planned objectives) }\end{array}$ & $\begin{array}{l}\text { Oversight (Monitor and review what has happened and } \\
\text { assess changes) }\end{array}$ \\
\cline { 2 - 2 } & Hindsight (Learn the right lessons from experience) \\
\hline $\begin{array}{l}\text { Act (Correct and improve plans to meet and } \\
\text { exceed planned results) }\end{array}$ & Act (Respond to and create disruptions and opportunities) \\
\hline
\end{tabular}

\subsection{Risk Management vs. Organizational Resilience}

According to Dahms (2010), "resilience is an organization's state of being, resulting from the management of uncertainty in a complex adaptive system". Traditional risk management processes focus on identifying potential risks, rather than managing them. In this context, a key priority for decision-makers should be to identify how risk management can be integrated and leveraged in order to achieve a high level of resilience. The dynamic character of organizational resilience was underlined by Sutcliffe \& Vogus (2003). They argue that resilience is developed over time by continually responding and mitigating risks, rather than reacting to specific interruptions or jolts. Moreover, Linkov, Trump \& Fox-Lent (2016) compared risk and resilience management, concluding that resilience analysis focuses on the unknown, uncertain, and unexpected facts, at the scale of a system and not by looking at the various parts, taken separately. In other words, a resilience-based approach involves identifying potential threats to system stability and taking the necessary measures to 
prevent long-term losses. Given the above, it can be inferred that resilience does not replace risk management. Rather, it can be said that it is the outcome of a sound risk management process, which promotes a new way of thinking that diverges from the traditional risk management perception. Another important aspect relative to resilience thinking is the varied approaches between risk and business continuity management. According to Krell (2006), risk management focuses on "pre-event" responses to perceived risks, while business continuity management focuses on the necessary processes that are implemented after an event or disaster occurs, so that the system can return to its normal operations as efficiently and effectively as possible.

\subsection{The Value of Internal Control in Organizational Resilience}

Internal control refers to a dynamic process, which is designed to support organizations in adapting to a complex, uncertain, and unstable environment (INTOSAI, 2004). An effective internal control system provides a powerful means of maintaining organizational resilience and cohesion during times of uncertainty and relative normality. Operational effectiveness and efficiency, together with reliable reporting, and compliance with legal and regulatory requirements, necessitate much more than rigorous adherence to policies and procedures. The key to an effective internal control system, is the contribution of management and personnel at all levels for addressing potential risks and providing a reasonable assurance that the mission of the organization and its general objectives are achieved (COSO, 2013). Reasonable assurance "equates to a satisfactory level of confidence under given considerations of costs, benefits and risks", while it "reflects the notion that uncertainty and risk relate to the future, which no one can predict with certainty" (INTOSAI, 2004). Focusing on internal control and its important role to the fields of Enterprise Risk Management, the Committee of Sponsoring Organizations of the Treadway Commission (COSO) introduced in 2013 the Internal Control Framework (Figure 2), a management tool that is generally embraced by organizations and the stakeholders that are associated with their operation.

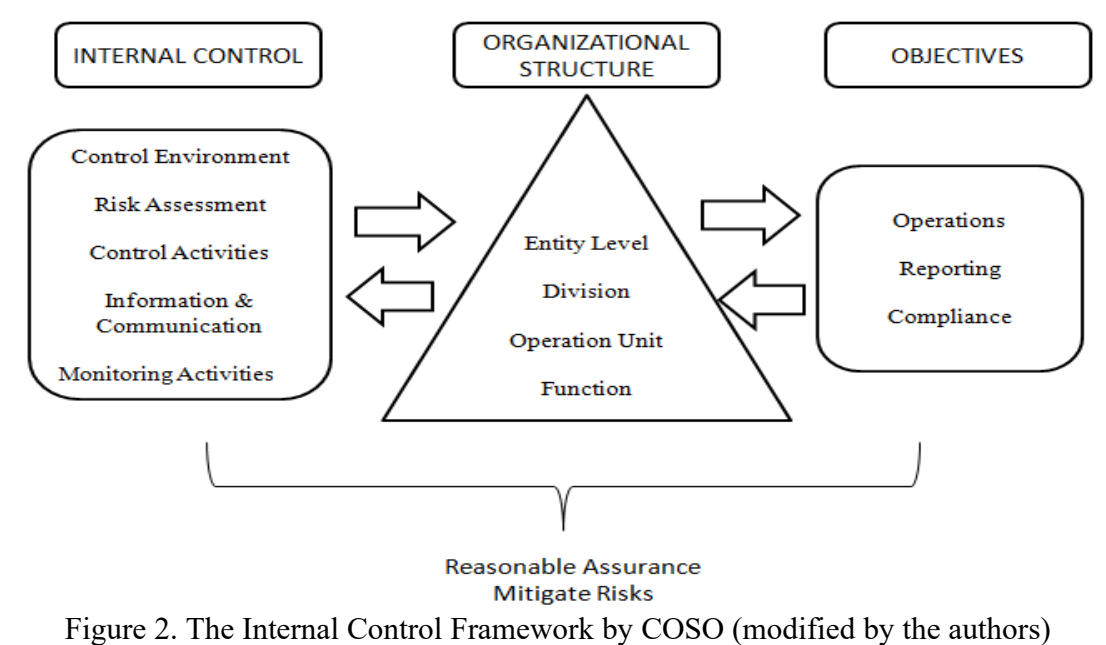

The structure of the five interdependent components of the framework, required for the achievement of the entity's objectives (i.e., operations, reporting, and compliance), at every level of the organizational structure (i.e., entity level, division, operational unit, or functions), create a multidirectional iterative model, which can reinforce the organization's capacity to manage change effectively (COSO, 2013). In summary, formal internal control processes within the traditional business management policies, build a robust risk management framework that assist organizations to increase their resilience capacity and strategic adaptability to changes in business, operating, and regulatory environments. 


\subsection{The Value of Internal Audit in Organizational Resilience}

Internal audit differs from internal control, as it is geared to provide independent assurance about the quality of risk management, corporate governance processes, and systems of internal control, as well as for evaluating the overall risk-based management system implemented by the organization as a whole (Chartered institute of Internal Auditors, 2019). As an independent, objective, and consulting activity, internal audit acts as a catalyst by providing advice to executive management, relative to the improvement of operational efficiency and effectiveness (Gurama \& Mansor, 2018). An effective internal audit system ensures that business risks are effectively addressed by management, and the alignment of risk mitigating actions relative to the strategic goals and objectives of the organization.

Strategic planning often fails as a result of a lack of a holistic understanding (on the part of decisionmakers) in regard to the relations that exist between the desired outcomes and the necessary conditions that drive outcomes. Resources are mostly exerted, focusing on the desired outcomes, rather than on the conditions under which these outcomes are achieved (Varsos \& Assimakopoulos, 2018). The complexity and volatility of the high-risk business environment should not be underestimated, as it relates to the viability of the organization. Instead, organizational capabilities should be developed to ensure tha

$\mathrm{t}$ the organization is going to be "future-proof" in a high-risk business environment. Moreover, internal auditing processes need to be implemented as a means to bridge the gap between the desired business resilience programs and the actual strategic goals of the organizations (Trollope, Atkinson, \& Carbone, 2019). As illustrated in Figure 3, a resilience-based approach in risk assessment and the integration of an agile internal control framework within the organization's structure, are two fundamental criteria for enhancing organizational resilience in the audit process.

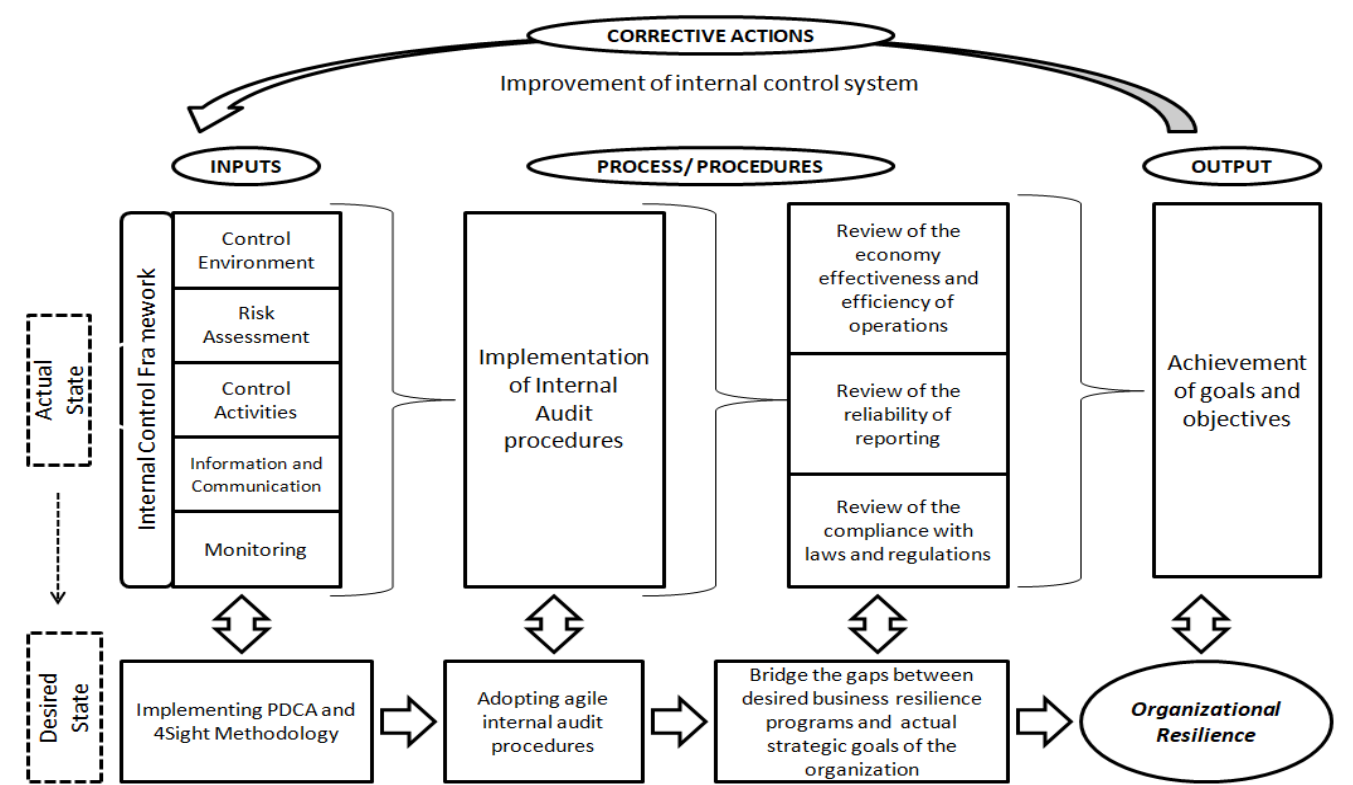

Figure 3. A systems view of the structural relationship between internal control and internal audit for enhancing organizational resilience. 


\section{THE VIABLE SYSTEM MODEL: A FRAMEWORK FOR UNDERSTANDING ORGANIZATIONAL RESILIENCE}

\subsection{The VSM: A Brief Overview}

The VSM was developed by cybernetician Stafford Beer, and described in his book Brain of the Firm (1972). The VSM draws on the physiology of the human nervous system and makes use of an elegant cybernetic description to define a network of purposeful activities and processes, which are organized to meet the demands for survival in a dynamic environment. Further, the VSM defines the various elements that are necessary for creating viable organizations, through an adequate balance between horizontal and vertical forms of communication and control. The VSM should not be confused with a functionally based organizational structure that is typically articulated through a conventional organogram (Varsos \& Assimakopoulos, 2018). The VSM draws on a number of fundamental tenets of cybernetics, including that of requisite variety.

\subsubsection{The Principle of Requisite Variety}

The Law of Requisite Variety holds that in order for a system to remain stable, the number of states of its control function must be at least equal to (or exceed) the number of states of the system being controlled (Ashby, 1956). Drawing on the Law of Requisite Variety, Beer argues that the variety of the environment axiomatically exceeds the variety of the operations, which in turn exceeds the variety of the metasystem that regulates or controls the operations. In order for the system to reach a homeostatic balance the metasystem needs to reduce (attenuate) the operations' variety and increase (amplify) its own variety in relation to the operations. In turn, the operations need to attenuate the environment's variety and amplify their own variety relative to the environment. The continuous loop structures that are illustrated in Figure 4, reflect an emphasis placed on homeostasis, which is sought as a balance through requisite variety (Varsos \& Assimakopoulos, 2018).
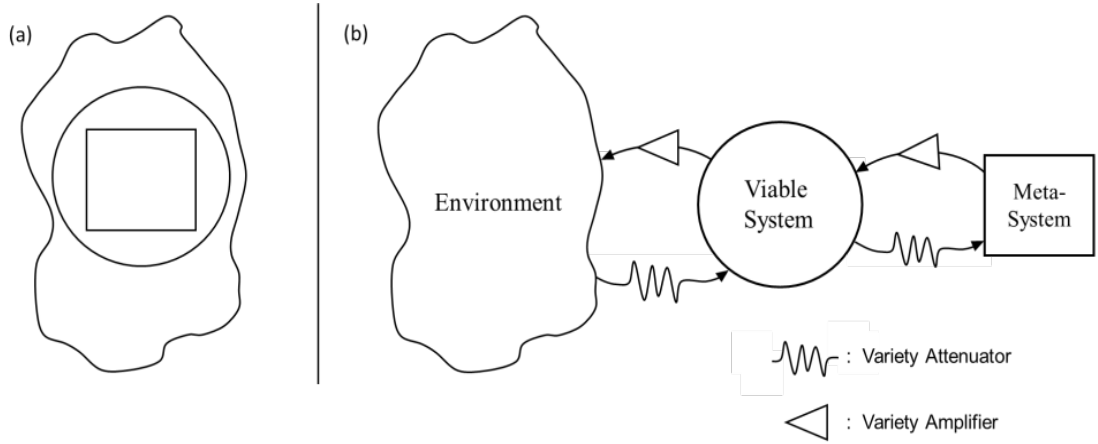

Figure 4. (a) The three fundamental components of the VSM. (b) Homeostatic Balance between the three components. Source: Varsos \& Assimakopoulos (2018).

\subsubsection{The Principle of Recursion}

The recursive nature of viable systems is based on Beer's Recursive System Theorem, which states that "in a recursive organizational structure, any viable system contains, and is contained in a viable system" (Beer, 1979). The principle of recursion supports that all viable systems are self-regulatory and self-organizing. They act autonomously with their environment, contributing to the production of a larger, also autonomous viable system. Consequently, viable systems are embedded in other viable 
systems at increasing levels of complexity (Espejo, 1990). All systems are recursive in nature. In this regard, every operational unit should adapt autonomously to the conditions of its local environment, while contributing to the synergy and cohesion of the organization as a whole (Varsos \& Assimakopoulos, 2018). Each operational unit's autonomy, therefore, should be constrained only to the extent that ensures that the synergy of the organization is not threatened (Zargar, Faghani, \& Mahmudi, 2011).

\subsubsection{The Five Subsystems}

Beer explains that every viable organism possesses five necessary and sufficient subsystems interactively involved that maintain the system's identity independently of other organisms within a shared environment (Beer, 1979; Rioz, 2010). The use of the words necessary and sufficient implies that all five (interdependent) subsystems must be present in a viable system and that no more than the five subsystems are necessary for viability. The five subsystems (of equal importance) are illustrated in Figure 5 and described in turn below.

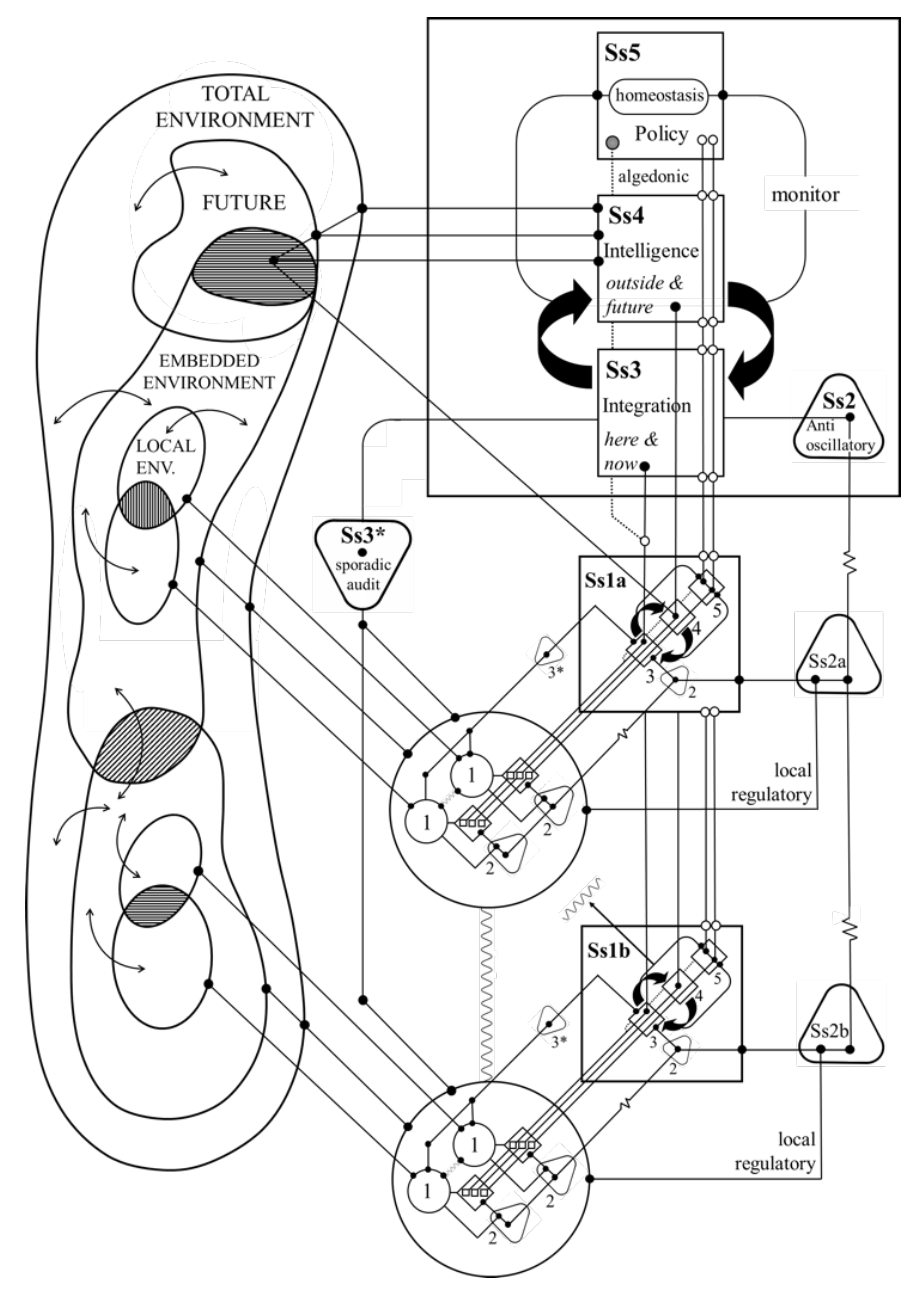

Figure 5. The Viable System Model. Source: Beer (1985). 
- System 1 (implementation) comprises all the primary units (e.g., divisions, business units) or operations of the organization that carry out the organization's actual production and/or service provision activities.

- System 2 (coordination) consists of a control center for each primary unit, as well as a supervisory control center at the top management level. This system has the function of a cybernetic spinal cord and ensures that through coordination-cooperation the activities of the primary units will not be mutually inhibitory.

- System 3(Integration) provides day-to-day optimization, ensuring that the sum activities of the primary units are carried out as a coherent unity. Integration relates to the internal and immediate processes, which assure the viable system's stability, consistency and continuity.

- System 3* (audit) concerns the monitoring and auditing function of the viable system, through which only the most important and relevant (aggregated) information from the local management of each primary unit is received. This function is necessary to maintain control, thus satisfying the condition of requisite variety.

- System 4 (intelligence) maintains a constant link with the total environment and gathers intelligence relating to developments that are likely to be relevant to the system in the future. Afterwards, it formulates recommendations that allow the primary units to adapt to the new conditions.

- System 5 (policy) monitors the homeostat between the functions of integration (system 3) and intelligence (system 4), ensuring that an effective balance is achieved between the two and provides the overall governance (policy) function for the entire system. Finally, it provides a logical closure to the viable system by asserting its identity (Varsos \& Assimakopoulos, 2018).

\section{DEVELOPING ORGANIZATIONAL RESILIENCE THROUGH THE VSM}

A viable organization, as expressed through the VSM, may be viewed as a complex multi-layered system that is composed of a bounded set of interconnected component parts (subsystems) that work together in order to achieve one or more desired outcomes. By virtue of their functions and interactions, the various subsystems contribute to the performance of the whole, even though they are functionally differentiated. Viability implies that the organization as a whole, and each subsystem of which the organization is composed, need to have the capacity to recognize and control its component parts and the relations that hold them together, to develop and implement effective communication networks and information flows among its component parts that reinforce cohesion and common purpose, and to harmonize its function with the internal and external contingencies that are relevant to their purpose (Varsos \& Assimakopoulos, 2018). The VSM, through its recursive structure, can be used to diagnose the strategic gaps in the existing structure of any organization, so that viable solutions for improving their adaptive capacity can be identified, making them more robust and agile. In short, the recursive structure of the VSM should be embraced, and the 4Sight (or other complimentary) methodology applied to the management of each set of recursive processes, ensuring the coherent interactions of these processes, so as to achieve their intended results in accordance with the overall risk tolerance and strategic direction of the organization. Management of the processes, in each recursive level, and the system as a whole can be achieved using the PDCA cycle, with an overall focus on risk-based thinking, aimed at taking advantage of opportunities and preventing undesirable results. 


\subsection{Setting Goals and Objectives}

A basic tenet of achieving organizational resilience, is identifying and communicating the need for change. This is carried out by assessing the current and the desired state of the organization, relative to the complexity of its internal and external business context. Having identified the boundaries, purpose, and relevant environment, of the structure that is targeted for change, a formal strategic plan needs to be developed, which includes the overall strategic goals of the initiative, and unambiguous targets in relation to the objectives that are sought. Management should develop and articulate a shared purpose, vision, mission, and values within the organization, as well as provide a coherent strategy for mitigating the actual and/or potential barriers to the plan's effective implementation. The plan should reflect specific principles, ethics, transparency and the responsible use of funds and resources (EFQM, 2012). Finally, the plan should enunciate the intervention rules and corporate and legal requirements, in a manner that ensures the creation of a shared culture of resilience, and the achievement of the organization's overall goals and objectives.

\subsection{Aligning Operations to the External Environment}

Strategic planning should include integration of innovative policies and forward planning, which are based on the organization's needs and the expectations of internal and external stakeholders (Walker, 1991). A formal cross-functional team with specific competencies, should explore viable solutions that are geared at increasing the organization's capabilities, within the context of both expected and emerging threats and opportunities. Business Intelligence (BI) technologies, like a technology portfolio, which support the organization's overall strategy, aiming at improving the agility of processes, projects and the organization, combined with the establishment and management of learning and collaboration networks, will help in gathering and analyzing data, as well as managing sufficient information and knowledge for effective decision-making (EFQM, 2012). Strategic decisions should be based on a sufficient understanding of the overall environment, and the organization's internal capabilities. Managing the organization's internal capacity, given the rate of change of its external business context, requires the cooperation and coordination among the various operations that compose the organization (Walker, 1991). In this context, the lack of a coherent strategy and/or ineffective processes, may contribute to a myopic assessment of the external business environment, which in turn may result in phenomena of "innovatism" or "conservatism", both of which are disadvantageous to the organization's viability. Should these phenomena emerge, it is management's responsibility to intervene, and restore the overall stability of the organization (Zargar, Faghani, \& Mahmudi, 2011).

\subsection{Balancing the Internal Environment}

Having formulated the organization's strategic goals and objectives (within the overall risk that is embedded in its business context and in line with the organization's risk tolerance), the degree of autonomy of each operational unit should be determined as a function of the organization's overall purpose. This determination should be made by the organization's top management, avoiding the inadvertent preservation of an existing state, despite the presence of circumstances that warrant change, or the premature introduction of change despite a lack of capacity (on the part of each operational unit) to effectively absorb the change. Having achieved a balance between preservation and change, management needs to disseminate to each operational unit the organization's legal and corporate requirements, (thus granting identity), allocate the means necessary to achieve their operational mandate through resource bargaining (thus granting a reasonable degree of autonomy), and hold each operational unit accountable for outcomes achieved. Management then needs to 
maintain an isometric bird's-eye-view of the operational units and provide integration and optimization, ensuring that the sum activities of their effort is carried out coherently. The effectiveness and efficiency of the processes that are carried out by the operational units should be verified through an internal control framework, combined with sufficient internal audit activities, thus ensuring that preventive and corrective actions are carried out, as circumstances warrant.

\section{CONCLUSION AND FUTURE RESEARCH}

In this work, an overview of organizational resilience was provided and the four cornerstones that define the concept were discussed. We additionally argued that resilience should be embraced as a holistic approach, which should be used to address both predictable and unforeseen risks, in a manner that augments traditional risk-management processes. Further, we stressed the significant role of the internal control and internal audit functions in integrating resilience into an agile organizational structure. We explored the dynamic character of organizational resilience with the use of the VSM, which provides a powerful alternative to the (top-down) hierarchical structures that often define the traditional approach to organization. The VSM embraces the position, which holds that an organization's viability is dependent on its ability to acclimate successfully to changing (internal and/or external) circumstances, as a unified whole. Moreover, the model exemplifies the importance of multidirectional information sharing and the significance of the information processing mechanisms, which transforms this information into valuable knowledge that can be used wisely to guide decisions and gage performance relative to desired outcomes. A model for the effective dissemination of information that promotes a resilient organizational structure, using the arrangements of the VSM, will be provided in a future publication.

\section{RÉFÉRENCES}

ACKOFF, R.L. (1971). "Towards a system of systems concepts”. Management Science, 17(11):661671.

ACKOFF, R.L. (1999). Recreating the corporation: A design of organisations for the 21st century. Oxford University Press, New York.

ADGER, W.N. (2000). "Social and ecological resilience: are they related?". Progress in Human Geography, 24(3): 347-364.

ALEXANDER, D.E. (2013). "Resilience and disaster risk reduction: an etymological journey". Natural Hazards and Earth System Sciences, 13: 2707-2716.

ARTHUR, W.B. (1999). "Complexity and the economy”. Science, 284 (5411): 107-109.

ASHBY, R.W. (1956). An introduction to cybernetics. Chapman \& Hall, London.

ASSIMAKOPOULOS, N.A. \& VARSOS, D.S. (2015). "A methodological systemic scheme using causal loops for the design and control of organisational change (DCSYM-2)". Int. J. Applied Systemic Studies, 6 (1): 1-25.

BARLAS, Y. (2007). System Dynamics: Systemic Feedback modelling for Policy Analysis. Encyclopedia of Life Support Systems: 1131-1175, Industrial Engineering Department, Boğaziçi University, Istanbul, Turkey. Retrieved November 22, 2019, from

http://web.boun.edu.tr/ali.saysel/ESc59M/BarlasEOLSS.pdf.

BEER, S.A. (1972). Brain of the firm. The Penguin Press, London.

BEER, S.A. (1979). The heart of enterprise. John Wiley, London and New York.

BURNARD, K. \& BHAMRA, R. (2011). "Organisational resilience: development of a conceptual framework for organisational responses". International Journal of Production Research, 49(18): 55815599. 
BURNARD, K., BHAMRA, R. \& TSINOPOULOS, C. (2018). "Building organizational resilience: Four configurations". IEEE Transactions on Engineering Management, 65(3): 351-362.

Chartered Institut of Internal Auditors (2019). “What is internal audit?”. Retrieved December 4, 2019, from https://www.iia.org.uk/about-us/what-is-internal-audit/\#diff.

Committee of Sponsoring Organizations of the Treatway Commission (COSO) (2013). Internal control - Integrated Framework: Executive Summary. Retrieved November 22, 2019, from

https://www.coso.org.

DAHMS, T. (2010). "Resilience and risk management". Australian Journal of Emergency Management, 25 (2):21-26.

DENYER, D. (2017). Organizational Resilience: A summary of academic evidence, business insights and new thinking. BSI and Cranfield School of Management, Cranfield.

EFQM Framework for Innovation Agencies (2012), INNO-Partnering Forum. Retrieved November 22, 2019, from

https://ec.europa.eu/easme/sites/easme-site/files/Paper-EFQM-framework-Innovation-Agencies.pdf.

ESPEJO, R. (1990). “The Viable System Model”. Systemic Practice and Action Research, 3(3) :219221.

ESPEJO, R. \& GILL, A. (1997). The viable system model as a framework for understanding organizations. Phrontis Limited \& SYNCHO Limited.

FLOOD, R.L. \& CARSON, E.R. (1988). Dealing with complexity: An introduction to the theory and application of systems science. Plenum Press, New York.

GIBSON, C. A. \& TARRANT, M. (2010). “A 'Conceptual Models' Approach to Organisational Resilience". Australian Journal of Emergency Management, 25(2):6-12.

GURAMA, Z. \& MANSOR, M. (2018). "Internal audit effectiveness in tax administration: a model proposition”. Journal of Advanced Research in Business and Management Studies, 12 (1): 70-73.

HOLLING, C.S. (1973). "Resilience and stability of ecological systems". Annual Review of Ecology and Systematics, 4: 1-23.

Internal Control Standards Committee (INTOSAI) (2004). Guidelines for internal control standards for the public sector. Brussels, Belgium.

KERR, H. (n.d.). Organizational Resilience: Harnessing experience, embracing opportunity (Whitepaper). BSI, United Kingtom. Retrieved November 22, 2019, from https://www.bsigroup.com/LocalFiles/en-GB/organizational-resilience/whitepaper-harnessingexperience-embracing-opportunity.pdf.

KRELL, E. (2006). "Business Continuity Management: Strategy". Society of Management Accountants of Canada (CMA-Canada).

LENGNICK-HALL, C. A. \& BECK T. E. (2009). "Resilience Capacity and Strategic Agility: Prerequisites for Thriving in a Dynamic Environment". Editors, Nemeth, C., Hollnagel, E.\&Dekker S.. Resilience Engineering Perspectives Preparation and Restoration Vol.2, CRC Press, London.

LINKOV, I., TRUMP, B.D. \& FOX-LENT, C. (2016). Resilience: Approaches to risk analysis and governance. IRGC Resource Guide on Resilience. Lausanne: EPFL International Risk Governance Center.

MANYENA, B., O'BRIEN, G., O'KEEFE, P. \& ROSE, J. (2011).“Disasterresilience: a bounce back or bounce forward ability?". Local Environment: The International Journal ofJustice and Sustainability, 16 (5): 417-424.

MATURANA, H.R. \& VARELA, F.J. (1980). Autopoiesis and Cognition: The Realization of the Living. D. Reidel Publishing, Dordrecht, Holland.

MAVHURA, E. \& MANYENA, B. (2018). "Spatial quantification of community resilience in contexts where quantitative data are scarce: The case of Muzarabani district in Zimbabwe". Geo:Geography and Environment, 5(2): 1-20. 
MORGAN, G. (1986). Images of Organization. Newbury Park, CA: Sage Publications.

NSW GovernmentTreasury (2018). "Organizational resilience:Practitioner guide for NSW public sector organizations", TPP18-07 Policy and Guidlines Paper. Retrieved September 27, 2019, from https://www.treasury.nsw.gov.au/sites/default/files/2018-09/TPP18

07\%20Organisational $\% 20$ Resilience $\% 20 \% 20$ Practitioner $\% 20$ guide $\% 20$ for $\% 20$ NSW $\% 20$ Public $\% 20$ S ector\%20Organisations $\% 20$-pdf.pdf.

PATRIARCA, R., Di GRAVIO, G., COSTANTINO, F., FALEGNAMI, A. \& BILOTTA, F. (2018). "An analytic framework to assess organizational resilience". Safety and Health at Work, 9(3): 265276.

RIOZ, J.P. (2010). "Models of organizational cybernetics for diagnosis and design". Kybernetes, 39 (9/10): 1529-1550.

SCOTT, W.R., \& DAVIS, G.F. (2007) Organizations and organizing: Rational, natural, and open systems perspectives ( $1^{\text {st }}$ ed.). Upper Saddle River, NJ: Pearson Prentice Hall.

SHARIFI, A. \& YAMAGATA, Y. (2016). "On the suitability of assessment tools for guiding communities towards disaster resilience". International Journal of Disaster Risk Reduction, 18: 115124.

SMITH, P. et. al (2011). "Network resilience: a systematic approach". In IEEE Communications Magazine, 49(7): 88-97.

SUTCLIFFE, K.M. \& Vogus, T.J. (2003). Organizing for resilience. Positive Organizational Scholarship: Foundations of a new discipline. Cameron, K.S., Dutton, J.E. \& Quinn, R.E.., San Francisco: Berrett-Koehler, 94-110.

TROLlOPE, C., ATKINSON, D. \& CARBONE, M. (n.d.). "The role of the internal auditor in business resilience: 1303A-16 Business Resiliency Article". The Institute of Internal Auditors, Canada. Retrieved November 22, 2019, from

https://chapters.theiia.org/IIA\%20Canada/Thought\%20Leadership\%20Documents/The-Role-of-theInternal-Auditor-in-Business-Resilience.pdf.

VARSOS, D.S., \& ASSIMAKOPOULOS, N.A. (2016). "A systems approach to alternative paradigms for organization and organizational change". Int. J. of Applied Systemic Studies, 6(4): 302-326.

Varsos, D.S. \& Assimakopoulos, N.A. (2018). "Viability and change in the twenty-first century organization: A cybernetic perspective". International Journal of Applied Systemic Studies, 8(2): 119150.

von BERTALANFFY, L. (1950). "An outline of general system theory". The British Journal for the Philosophy of Science, 1(2): 134-165.

WALKER, J. (1991). The Viable Systems Model a guide for co-operatives and federations. Retrieved November 29, 2019, from https://www.scribd.com/document/136364750/Jon-Walker-VSM-a-Guidefor-Co-Operatives-and-Federations.

WOODS, D.D. (2015). "Four concepts for resilience and the implications for the future of resilience engineering".Reliability Engineering \& System Safety, 141:5-9.

WOUTER, A., DE SMET, A., LACKEY, G., LURIE, M. \& MURARKA, M. (2018). The five trademarks of agile organizationsreport. Agile compendium, McKinsey \& Company. Retrieved November 22, 2019, from

https://www.mckinsey.com/ /media/McKinsey/Business\%20Functions/Organization/Our\%20Insights/ Harnessing\%20agile\%20compendium/Harnessing-Agile-compendium-October-2018.ashx.

ZARGAR, S.M., FAGHANI, K. \& MAHMUDI, G. (2011). "Assessing the role of the EFQM excellence model in organizational viability". World Applied Sciences Journal, 14(7): 987-995. 
